\title{
SOIL DEGRADATION OF DIAZINON AND ITS EFFECT ON THE EMERGENCE OF APPLE LEAFCURLING MIDGE
}

\author{
J.T. SMITH, R.B. CHAPMAN and C.M. FRAMPTON
}

\section{Ecology \& Entomology Group, Lincoln University, P.O Box 84, Canterbury}

\begin{abstract}
The degradation of diazinon residues in the soil of an orchard on the Waimea Plains, Nelson was determined. The half life of diazinon varied significantly between 12.2 and 27.7 days, depending on the time of application. Soil applications of diazinon had a significant effect on the emergence of adult apple leafcurling midge (ALM) (Dasineura mali Diptera: Cecidomyiidae). More ALM were captured in the control and plots treated with diazinon on 7 September than in plots treated with diazinon on 21 September and 5 October.
\end{abstract}

Keywords: soil degradation, apple leafcurling midge,Dasineura mali, diazinon.

\section{INTRODUCTION}

Diazinon is a broad spectrum organophosphate insecticide which is commonly used on New Zealand apple orchards specifically for the control of apple leafcurling midge (ALM) (Dasineura mali Diptera: Cecidomyiidae) (Smith and Chapman 1995; Tomkins et al. 1994). It is often applied as a foliar spray, although many orchardists make soil applications during late winter or early spring in an attempt to control overwintering ALM pupae or emerging adults. To date, no experiments have been reported on the efficacy of diazinon ground applications for ALM control. Therefore, it is necessary to determine the most effective timing for soil applications. Of equal importance is the need to investigate the persistence of diazinon in orchard soil to meet the requirements of integrated fruit production standards (Batchelor et al. 1997).

This paper reports a study to investigate the most effective timing of soil applications of diazinon for suppressing ALM populations and the persistence of diazinon when applied directly to the soil.

\section{MATERIALS AND METHODS}

A conventionally-managed 'Royal Gala' apple cultivar block on the Waimea Plains, Nelson was used for this investigation, as it had no previous ground applications of diazinon, and a relatively high population of ALM in the 1995/96 season. The soil type was a Ranzau stoney loam.

Diazinon $600 \mathrm{EW}$ was applied to the soil on plots of approximately $56 \mathrm{~m}^{2}$ at a rate of 4 litres / 1000 litres water per hectare $\left(0.24 \mathrm{~g}\right.$ of a.i. per $\left.\mathrm{m}^{2}\right)$ using a knapsack sprayer. Four treatments were compared, with single diazinon applications made on three dates, compared to an untreated control. In treatment 1 , the diazinon application was made on 7 September 1996, in treatment 2 on 21 September, and in treatment 3 on 5 October 1996. Treatment 3 occurred one week before full bloom to prevent any bee toxicity. There were three replicates of each treatment arranged in a randomised complete block design.

For each treatment, two emergence traps (Smith and Chapman 1996) were randomly placed under trees no more than $1300 \mathrm{~mm}$ from the tree trunk on 25 September 1996. Each week until 15 January 1997 the sticky petri dish lid trapping surface was replaced. The lids were examined with a binocular microscope and the number of ALM adults recorded. The emergence traps were relocated on the 18 November 1996, as traps prevent mature larvae from pupating in the soil beneath the trap. The relocation ensured that emerging adults of the next generation would be 
captured. Two periods of adult emergence occurred during the investigation; the first from 25 September to 18 November 1996 (seven weeks), and the second from 18 November 1996 to 15 January 1997 (eight weeks). The numbers of ALM adults captured in emergence traps in diazinon treatments were compared using ANOVA.

From each of the twelve diazinon-treated plots described earlier, twenty soil core subsamples (diameter $20 \mathrm{~mm}$, depth $50 \mathrm{~mm}$ ) were removed and combined into one sample 1, 7, 14, 21, 35, 49, 63 and 84 days after diazinon application. One set of subsamples was taken before each diazinon application as a control. Soil samples were analysed for diazinon residues by the Plant Protection Research Unit, Lincoln Ventures Ltd, using a variation of the PPRU/SOP 4.04 method as derived from the standard AOCA method 29.013 (1984) and quantified using GCMSD (L.H. Banks pers. comm.). The limit of detection for diazinon was $0.01 \mathrm{mg} / \mathrm{kg}$.

The decline in residue levels was modelled as exponential decay. The residue data were transformed by natural logarithms and linear regression (log residue vs time) was conducted with each replicate to obtain the decay rate as the slope of the regression. The slopes were used to calculate the half-life values for each replicate. Half-lives were analysed using ANOVA.

\section{RESULTS}

The mean number of ALM adults caught in emergence traps during the first trapping period was significantly different between treatments (df 3,20$)$ (Table 1). No adults were caught in emergence traps in treatments 2 and 3. No significant difference occurred between treatments during the second trapping period (df 3,20$)$, however, more ALM adults were trapped in the second trapping period compared with the first (Table 1).
TABLE 1: Mean ( \pm SE) number of ALM adults captured in emergence traps per week for each treatment during the first and second trapping periods.

\begin{tabular}{lcccc}
\hline Treatment & \multicolumn{2}{c}{$\begin{array}{c}\text { First trapping period } \\
\text { (Sep 25 - Nov 18) }\end{array}$} & $\begin{array}{r}\text { Second trapping period } \\
\text { (Nov 18 - Jan 15) }\end{array}$ \\
\hline Control & 1.33 & $(0.50)$ & 7.50 & $(2.40)$ \\
Diazinon applied on Sep 7 & 0.50 & $(0.30)$ & 5.83 & $(2.70)$ \\
Diazinon applied on Sep 21 & 0.00 & $(0.00)$ & 5.17 & $(1.40)$ \\
Diazinon applied on Oct 5 & 0.00 & $(0.00)$ & 2.50 & $(0.70)$ \\
Significance & \multicolumn{3}{c}{$*$} & \multicolumn{2}{c}{ NS } \\
\hline
\end{tabular}

${ }^{1}$ Significance: NS P $>0.05, * \mathrm{P}<0.05$.

The diazinon decay rates were significantly different between treatments (df 2,6, $\mathrm{P}<0.001$ ) (Figure 1). Treatment 1 had the slowest decay rate (slope $\pm \mathrm{SE},-0.025 \pm$ $0.001)$, treatment 2 was intermediate $(-0.048 \pm 0.002)$ and treatment 3 was the most rapid $(-0.057 \pm 0.002)$ (Figure 1$)$. There was a significant difference (df 2,6, $\mathrm{P}<0.001)$ between the calculated half-lives for the different diazinon treatments. The mean $( \pm \mathrm{SE}$ ) half-life of treatment 1 was $27.7 \pm 1.23$ days, compared to $14.5 \pm 0.74$ and 12.2 \pm 0.45 days for treatments 2 and 3 respectively.

\section{DISCUSSION}

More ALM adults were captured during the first trapping period in the control and treatment 1 than in treatments 2 and 3 . This suggests that the later applications were more effective at controlling ALM. Although, the decay rate of diazinon residues in treatment 1 were the slowest, it is possible they had declined to a non-toxic level before the emergence of adults. The diazinon was applied in treatment 1 on the 7 September and other studies have estimated peak egg laying (hence adult emergence) occurs in the Nelson district at the end of September (Smith and Chapman 1997) i.e., two weeks 


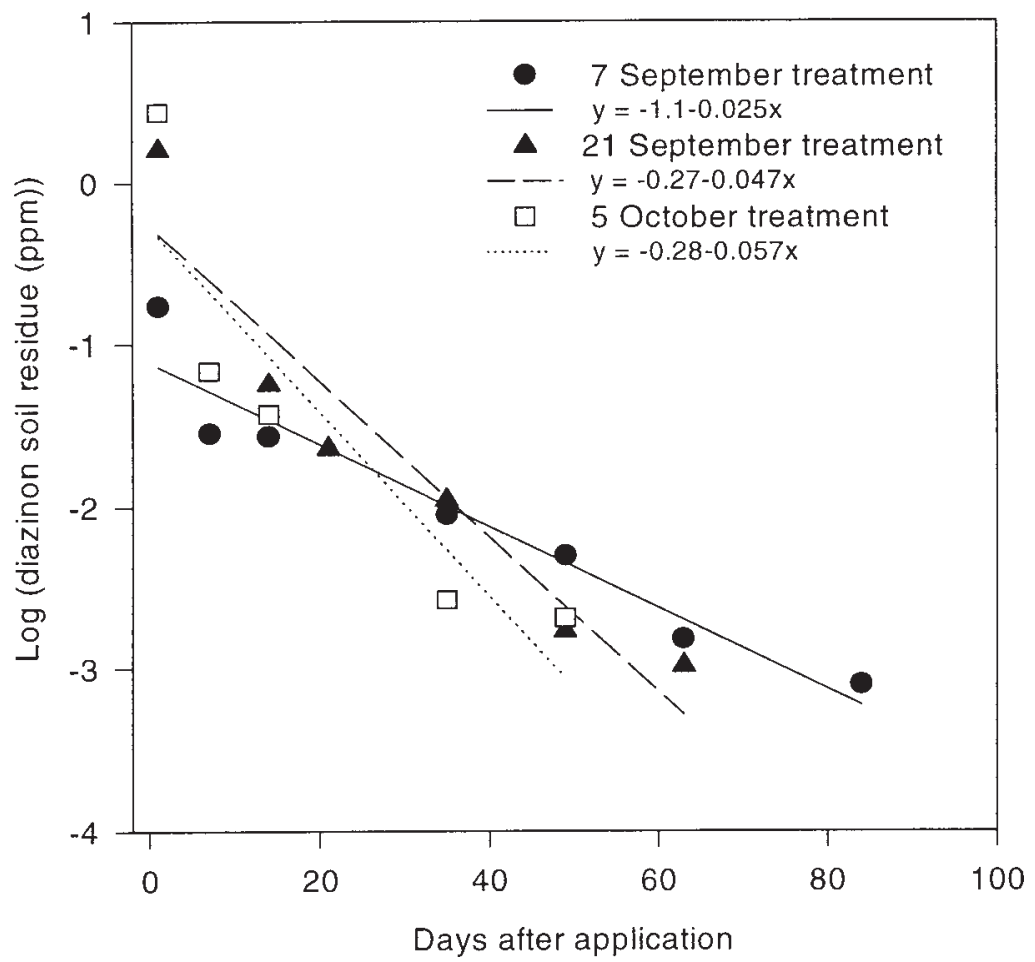

FIGURE 1: Regressions for diazinon residue levels over time in an apple orchard, Waimea Plains, Nelson.

after the application of diazinon. The decay rates calculated in Figure 1 show that 14 days after the first application, approximately $0.7 \mathrm{ppm}$ of diazinon would be present in the soil. The later diazinon applications in treatments 2 and 3 would have been closer to the estimated adult emergence, therefore have higher diazinon residues and potentially more effective insecticidal action.

For the second trapping period, no significant difference in emergence trap catches occurred between any application times. The residue analysis showed that only $0.35,0.26$, and $0.45 \mathrm{ppm}$ of diazinon would be present in the soil for treatments 1,2 and 3 respectively, at the start of the second trapping period. These low residue values would most likely have little effect on the survival of ALM. Nevertheless, a trend of declining numbers of ALM captured with successive diazinon applications was observed during the second trapping period, although there was high variability between individual trap catches.

The rate of diazinon decay varied following each application time. This difference was unlikely to be caused by variations in soil type, as diazinon has been shown to follow a similar decay pattern in soils ranging from an organic muck through to sandy loam (Getzin and Rosefield 1966). Soil moisture, which may influence the toxicity of diazinon to insects (Harris 1967), would have been relatively constant over all plots during the experiment and is therefore unlikely to have influenced the decay rate. The diazinon application in treatment 1 was made in early September and residues were recorded for 11 weeks. Local meteorological data showed that the average soil temperature during that period was $12.1^{\circ} \mathrm{C}$ (Agfirst 1998). By comparison, the soil 
temperatures following the diazinon applications in treatments 2 and 3, averaged $12.8^{\circ} \mathrm{C}$ and $13.8^{\circ} \mathrm{C}$ respectively (Agfirst 1998). Higher temperatures are known to accelerate the non-biological degradation of diazinon (Bartsch 1974), and Tate (1970) warned that diazinon did not have sufficient persistence to control carrot rust fly if used in warm soils (over $15^{\circ} \mathrm{C}$ ). Bro-Rasmussen et al. (1968) claimed that an essential part of diazinon degradation was caused by the activity of micro-organisms and since temperature affects the activity of soil micro-organisms (McLaren and Cameron 1990) they would, in turn, affect diazinon degradation. These reports, combined with the meteorological data, support the view that soil temperature was a most likely cause of the differences in diazinon decay found in this study.

The importance of correct timing for diazinon applications for control of ALM is clearly indicated. If an orchardist applied diazinon to the soil too early, residues may be too low for any insecticidal action on the later emerging ALM adults. This study also supports the view that diazinon applied to the soil may target emerging ALM adults. If ALM pupae were the most vulnerable stage, varying the timing of the diazinon application should have little effect on the number of ALM captured in emergence traps as ALM pupae would always be present in the soil. In practical terms orchardists should time their soil-applied insecticide as close to the emergence of ALM adults as practical, which, in turn, will reduce egg laying on newly emerged foliage. Ground based applications of diazinon will persist longer than those on the foliage and would potentially reduce the initial infestation of ALM. However, soil applications would not suppress ALM adults coming from neighbouring orchards and whether they provide any long term suppression of ALM numbers is uncertain.

\section{REFERENCES}

Agfirst Consultants Nelson Ltd. 1998. Meteorological Reference Data Base, P.O. Box 33, Motueka, New Zealand.

Bartsch, E. 1974. Diazinon II. Residue in plants, soil and water, p 51. In: Residue Reviews, F.A. Gunther and J.D. Gunther (Eds); New York, Springer-Verlag.

Batchelor, T.A., Walker, J.T.S., Manktelow, D.W.L., Park, N.W. and Johnson, S.R, 1997. New Zealand integrated fruit production for pipfruit - charting a new course. Proc. 50th N.Z. Plant Prot. Conf:: 14-19.

Bro-Rasmussen, F., Noddegaard, E. and Voldum-Clausen, K. 1968. Degradation of diazinon in soil. J. Sci. Food Agr. 19: 278-282.

Getzin, L.W. and Rosefield, I., 1966. Persistence of diazinon and zinophos in soils.J. Econ. Entomol. 59: 512-516.

Harris, C.R., 1967. Further studies on the influence of soil moisture on the toxicity of insecticides in soil. J. Econ. Entomol. 60: 41-44.

McLaren, R.G. and Cameron, K.C., (eds). 1990. Soil Science. Auckland: Oxford University Press. 294 pp. 1st ed.

Smith, J.T. and Chapman, R.B., 1995. A survey of apple leafcurling midge (Dasyneura mali) in the Nelson district. Proc. 48th N.Z. Plant Prot. Conf:: 117-120.

Smith, J.T. and Chapman, R.B., 1996. Comparison between emergence and egg laying in apple leafcurling midge (Dasyneura mali). Proc. 49th N.Z. Plant Prot. Conf.: 48-51.

Smith, J.T. and Chapman, R.B. 1997. Apple leafcurling midge egg laying on different apple cultivars and orchard properties on the Waimea Plains, Nelson. Proc. 50th N.Z. Plant Prot. Conf:: 247-251.

Tate, K.G., 1970. Carrot rust fly control with diazinon. Proc. 23rd N.Z. Weed and Pest Control Conf: : 209-213.

Tomkins, A.R., Wilson, D.J., Hutchings, S.O. and June, S., 1994. A survey of apple leafcurling midge (Dasyneura mali) management in Waikato orchards. Proc. 47th N.Z. Plant Prot. Conf:: 346-349. 